\title{
Inaccuracies in titles on bibliometrics in biomedical journals
}

Rafael Aleixandre-Benavent / Vicent Montalt Resurrecció / Juan Carlos Valderrama-Zurián Response to Hartley's comments on “Inaccuracies in titles on bibliometrics in biomedical journals"

We thank Dr. Hartley for his comments (Hartley 2015) and the opportunity to clarify a number of points from our work. We would like to correct two inaccuracies in Dr. Hartley's letter. First, our work does not analyse "titles of articles published in bibliometric journals" but "titles of articles on bibliometrics published in biomedical journals". Secondly, the surname of the second author is not Mantalt, but Montalt. We acknowledge that the term "inaccuracy" may not be the most appropriate to encompass some of the categories included in our analysis. We also acknowledge that, as Dr. Hartley points out, titles vary in length, format and purpose, and some formats are more popular than others in certain disciplines. Nevertheless, we firmly believe that the language used in the titles of articles in biomedical journals should be precise and accurate, and should avoid the types of ambiguity and imprecision exemplified in most of the titles mentioned in our article. This is consistent with what is prescribed in the style manuals of the main bodies dealing with accuracy in biomedical language. Our argument is based on the norms and recommendations established by the following authors and associations. The style manual of the American Medical Association states that titles should be concise, specific, informative and should contain keywords that represent the content of the articles. Authors are encouraged to avoid titles which are too general, too specific or contain strange words, questions or abbreviations (AMA 2007). Similarly the recommendation of the International Committee of Medical Journal Editors in its Recommendations for the Conduct, Reporting, Editing and Publication of Scholarly Work in Medical Journals explicitly states: "The title provides a distilled description of the complete article and should include information that, along with the abstract, will make electronic retrieval of the article sensitive and specific" (ICMJE 2014). BioMed Central, a Science, Technology and Medicine publisher of 272 peerreviewed open access journals, recommends making the titles and abstracts as concise, accurate, readable and informative as possible, and including words that potential readers of the article are likely to use during a search (BioMed Central 2014). Social Science Space, the online social network sponsored by SAGE publications (http://www.sagepub.com/home.nav) warns that "Clearly many authors believe that there is some kind of professional obligation on them as academics to be deliberately and carefully obscure, to choose titles that convey as little as possible to potential readers about what their text says" (Social Science Space 2014). In addition, innacurate titles may be particularly misleading for non-native speakers of the language and may cause unnecessary problems when translated into other languages. As Hartley (2008: 26) rightly points out: Irony, puns, humour, and literary and cultural references are difficult for non-native speakers of the language to understand. They are probably best avoided in the titles of academic articles. So too are titles containing acronyms-abbreviations accepted as words, for example 'Mental health for IAG providers' (IAG stands for information, advice and guidance)-and neologisms-words invented to describe a new phenomenon. (p.26) In short, to ensure fast and effective information retrieval and global understanding, scientific articles should have titles that accurately reflect their content and should eschew eccentric words and phrases (Hartley 2005; Hays 2010). 